\title{
CINE Y LITERATURA: NARRATIVA DE LA IDENTIDAD*
}

\author{
al \\ Alejandra Laverde Román ** \\ Martha Ligia Parra ${ }^{* *}$ \\ Alejandra Montoya Giraldo ${ }^{* * *}$ \\ Yennifer Uribe Alzate \\ Margarita Tobar Álvarez
}

Recibido: 15 de marzo de 2010. Aceptado: 24 de abril de 2010.

\section{RESUMEN}

Este artículo es resultado de la investigación La narrativa literaria y audiovisual en la construcción de la identidad cultural colombiana. Una mirada desde el cine y la literatura: adaptaciones de obras literarias llevadas al cine entre 1920 y 2008-1. En el presente texto se desarrolla un análisis de la relación de cine y literatura en la construcción de la identidad colombiana, a partir del rastreo bibliográfico de la crítica y las historias literarias y cinematográficas a un corpus seleccionado de obras literarias llevadas al cine.

Palabras clave: cine, literatura, identidad, crítica, adaptaciones cinematográficas, Colombia.

Este artículo de investigación científica y tecnológica, es resultado de la investigación "La narrativa literaria y audiovisual en la construcción de identidad cultural colombiana. Una mirada desde el cine y la literatura", adaptaciones de obras literarias llevadas al cine entre 1920 y 2008- 1, patrocinada por la Universidad de Medellín.

.* Comunicadora social-periodista, Universidad de Antioquia. Magíster en Literatura Colombiana, Universidad de Antioquia. Coordinadora Maestría en Comunicación, Universidad de Medellín.E-mail: alaverde@udem.edu.co

.... Comunicadora social-periodista, Universidad Pontificia Bolivariana. Crítica de cine, columnista El Tiempo, colaboradora de Kinetoscopio.

.... Auxiliar de investigación, estudiante noveno semestre de Comunicación y Lenguajes Audiovisuales.

..... Auxiliar de investigación, estudiante noveno semestre de Comunicación y Lenguajes Audiovisuales.

...... Auxiliar de investigación, estudiante noveno semestre de Comunicación y Lenguajes Audiovisuales. 


\section{CINEMA AND LITERATURE: IDENTITY NARRATION}

\section{RESUMEN}

This article is the result of the research "Literary and Audiovisual Narration in the Construction of Colombian Cultural Identity. A look from the cinema and the literature: Adaptations of literary works taken to the cinema between 1920 and 2008-1. In this text, an analysis of cinema-literature relation in the construction of Colombian identity, from the bibliographic consultation of criticism, literary and cinematographic stories to a corpus selected from literary works taken to the movies is developed.

Key words: cinema, literature, identity, criticism, cinematographic adaptations, Colombia. 


\section{INTRODUCCIÓN}

En un comienzo fue la literatura. Y en los inicios del cine, la literatura apoyó su crecimiento y desarrollo. Hoy, ese nexo se conserva e incluso sigue más vigente que nunca en una relación que ha sido tan estrecha como difícil, tan antigua como necesaria, tan apasionante como actual. Dos lenguajes distintos y una misma vocación narrativa. Como lo señala José Luis Sánchez Noriega: "Dentro de la relaciones cine-literatura, la adaptación es la gran cuestión, tanto desde el interés del debate cultural como desde el análisis de las formas artísticas" $(2006,18)$.

La relación entre ambos es compleja por la comparación a la que se les somete; el espectador siempre acude a la sala de cine en busca de los personajes que su inquieta imaginación ha formado, de los espacios creados en los ratos de lectura y que responden en ocasiones a otros referentes de su entorno, o tal vez a algún lugar visto en un viejo filme, un lugar de la niñez, en fin, todas las posibilidades que su vida y su experiencia le han provocado.

El crítico o el estudioso, cada uno en su disciplina o arte, buscan las características propias de cada ámbito para llevar a cabo la comparación que en ocasiones resulta inconveniente para la literatura o para el cine; personajes, espacios, narradores, temas y sentidos de la obra literaria se analizan en el filme, se evalúa la fidelidad o no al texto literario para dictar una sentencia a favor o en contra.

En fin, el director que emprenda la empresa de llevar una obra literaria al cine sabe que será evaluado, que se somete a la crítica del que conoce y del que intuye porque con mayores o menores elementos para ello, todo el que ha leído el libro se convierte en juez de la cinta cinematográfica.

En lo que sí suele haber coincidencia entre estudiosos, críticos, realizadores, directores, escritores, guionistas y espectadores es en que ambos, tanto el relato cinematográfico como el literario cumplen un papel dentro de la representación y construcción social de los países en los que están insertos. En el cine y en la literatura como formas de expresión podemos reconocer las señas particulares de una sociedad. Independiente de la intencionalidad explícita de una obra literaria o de una pieza audiovisual, su discurso narrativo hace visibles los códigos propios que particularizan y diferencian esa sociedad.

Por una parte, la obra literaria se ha constituido como medio de búsqueda de la identidad, ya sea individual, colectiva o cultural -es el caso de la nueva literatura latinoamericana de las décadas del 60 y 70- pero es un proceso que se venía dando desde décadas atrás, 30 y 40, y que continúa hasta las décadas posteriores. De igual manera, la narrativa audiovisual sufre un proceso paralelo en los diferentes países latinoamericanos. Países con mayor tradición cinematográfica empiezan a proponer una identidad latinoamericana alrededor de sus expresiones culturales populares; las películas mexicanas y argentinas difunden sus propuestas por el resto de América Latina, pero, sobre todo, nos hacen sentir más cerca, parte de un todo. Los medios acortan las distancias y promueven la sensación de hacer parte de algo mayor.

El cine y, sobre todo, la televisión más que la literatura son medios ideologizantes, en muchas ocasiones con un tono dominantemente moral que raya en el maniqueísmo, ya que tienen una función más clara con la construcción de los valores sociales y la cultura que los rodea; ambos tienen su parte en la construcción de los gustos y las imágenes sociales; se podría decir que más allá de informar, está la idea de formar. De igual manera, es claro que cada medio y expresión tiene sus lenguajes propios, su naturaleza y recursos técnicos y narrativos que les permiten proponer, cada uno desde sus posibilidades, creaciones narrativas diferentes.

El proceso continúa en las décadas siguientes en las que se plantean otros escenarios; con la llegada del neoliberalismo y los avatares de la globalización, las nuevas producciones se abrie- 
ron a la internacionalización, a la exportación de películas. Esta misma internacionalización lleva a preguntarse por la construcción actual de la identidad cultural en un mundo que diluye sus límites territoriales. La pregunta ha sido planteada por Néstor García Canclini: ¿pueden ser aún el arte y las comunicaciones masivas escenarios de identidad nacional? Este cuestionamiento formulado plantea la duda sobre la construcción de la identidad por parte del arte y las comunicaciones en un mundo globalizado que pierde o desdibuja los límites no sólo geográficos sino nacionales, regionales y locales.

\section{NARRATIVA E IDENTIDAD COLOMBIANA}

El cine colombiano, en consonancia con este pasado primigenio del séptimo arte, en sus inicios se sirve de las letras como medio eficaz para conectarse con los espectadores, para empezar a construir desde lo audiovisual la identidad cultural colombiana. En este sentido, es relevante la relación que han establecido desde su origen el cine y la literatura -apenas inicia el cine sonoro en los años veinte e inmediatamente las novelas, cuentos y otras narraciones son adaptadas al lenguaje cinematográfico-: en ambos se habla de la búsqueda de la identidad cultural nacional.

El cine se presenta ahora de otra manera, cada vez más personas prefieren ver las películas en sus casas -ya sea por cable o alquiladas en videotiendas- pero el cine nacional se oferta menos en estos lugares, así que el público nacional recibe con regularidad el cine de otros países y otras culturas. Por otra parte, está el papel del Estado que cede a empresas privadas la industria audiovisual, que son realmente las encargadas del desarrollo de las dinámicas culturales con repercusiones masivas; por ello Canclini vuelve a plantear: ¿̇cuál puede ser el papel del interés público y de las culturas nacionales si se deja en manos privadas, con objetivos predominantemente comerciales y trasnacionales, el conjunto de la televisión, el vídeo y otras tecnoculturas asociadas? (255). La internacionalización y la apertura económica llevan la discusión hacia nuevos puntos de vista; cuando hasta hace poco se discutía la modernidad y la tradición como cuestiones relevantes en el estudio de la identidad, ahora la pregunta va dirigida hacia la repercusión de los intereses globales y de mercado sobre el desarrollo cultural tradicional y moderno. La cuestión de fondo desarrollada por Canclini es: ¿quién nos va a contar la identidad? En este estado de cosas, lo anterior lleva a replantearse las formas de construcción de la identidad. Persiste un interés por las culturas concretas e identidades culturales de grupos específicos, ¿cómo van los medios a relatarlas? Posiblemente teniendo en cuenta que la identidad se construye con la interacción de diferentes contextos, por ello "los medios masivos que nacieron asociados a la reubicación transcultural de las comunicaciones no están mal preparados para actuar" (262).

La otra pregunta obvia es qué es identidad, el concepto es básico para entender de qué se habla y establecer desde qué perspectiva se parte. La identidad empezó a ser estudiada desde la Antropología se definió como los rasgos generales que caracterizan a una persona o grupo social, por ello, cuando se habla de identidad se habla también de diferencia de la relación con el otro. Se estableció que los habitantes de un cierto espacio debían pertenecer a una sola cultura homogénea y tener por lo tanto una única identidad distintiva y coherente. La cultura propia se formaría en relación con un territorio y se organizaría conceptual y prácticamente gracias a la formación de colecciones de objetos, textos, rituales, con los que se afirmarían y reproducirían los signos que distinguen a cada grupo. Se estableció que tener una identidad equivalía a ser parte de una nación, una identidad espacialmente delimitada, donde todo lo compartido por quienes la habitaban -lengua, objetos, costumbres- los diferenciaría en forma nítida de los demás (García Canclini, 1995: 92-93).

Luego, el concepto se extendió por las diferentes ciencias sociales y humanas acompañado de la idea de cultura; esta última convertida en una palabra de uso frecuente y ligero, sin embargo, en sentido concreto esta palabra es compleja, 
especialmente si hablamos de identidad cultural. Según Hamelink la identidad cultural es un término inadecuado y no es análoga a la identidad de los seres humanos, ésta debe ser entendida como personalidad individual. Mientras que la identidad cultural hace referencia a lo que la cultura es, este razonamiento implica que sería posible aislar a un individuo de una cultura determinada y éste tendría unas características establecidas. Por ello, se plantea que cada país tiene diferentes culturas y cada cultura distintas identidades, por lo tanto, sería más acertado hablar de identidades culturales que de identidad cultural. Por ello, es válida la pregunta de Catalina González en su ensayo Identidad, alteridad y comunicación: Definiciones y relaciones. ¿No podríamos más bien pensar que el concepto identidad (al igual que el concepto "cultura") se refiere a un conjunto de rasgos en permanente construcción, cuyo límite es cada vez más vulnerable y vulnerado por los mensajes de los medios de comunicación, los cuales introducen y sacan elementos al conjunto, para elaborar sus propios relatos de identidad? (González, 1997:80), ¿Cómo intervienen los medios de comunicación en la formación de la identidad? Concretamente nos refiere a la idea de ser entes socializadores que participan en la construcción de las diversas identidades personales y culturales; además, el proceso es cambiante porque la interacción social es continua, de tal suerte que los medios proponen paradigmas de identidad dentro y fuera de una cultura determinada. Es decir, intraculturales serían los modelos de identidad dentro de una cultura específica -géneros, juventud- y extraculturales los estereotipos de personas de otras culturas distintas a la propia.

En definitiva, los medios de comunicación se convierten en abastecedores de identidades con los que las personas van sintiéndose identificadas o diferenciadas y les permiten, además, encontrar un cierto apoyo para la adscripción a determinada identidad (Alsina, 1996:45). Otro aspecto a considerar es la relación entre interpretación y el individuo, en la diversidad de lecturas e interpretaciones. Umberto Eco ha planteado en la teoría general de la interpretación que no existe una sola lectura, sino tantas lecturas como intérpretes y tantos textos como lectores. En consecuencia, si entendemos la identidad como una construcción -"relato"- en gran parte elaborada por la relación de comunicación "uno-medio masivo-otro", ésta en tanto construcción mental del receptor, es múltiple, ya que no es otra cosa que una posible interpretación de un texto. Y, llevando al límite el planteamiento, si hay tantas interpretaciones como textos y lectores, debe haber, asimismo, tantas identidades como "otros-intérpretes" (González, 1997:79). De esta manera, se expresa una identidad como la colombiana que es multicultural y multiétnica.

Un país posee varias culturas y cada cultura varias identidades. Por ello, es válida todavía la pregunta por la relación de los géneros narrativos -novela y cine-y su papel en la construcción de la identidad cultural colombiana. En este sentido, se formula un proyecto de investigación que centra su interés en la forma como se construye esta identidad desde la narrativa, específicamente, en las adaptaciones literarias al cine que se presentan como posibilidad de síntesis de ambas narraciones, es decir, cuáles son los mecanismos que se emplean para hacerlo y las diferencias en este sentido que se encuentran entre ambas.

Para empezar la investigación realiza una selección representativa de los textos narrativos literarios llevados al cine entre 1920 y el primer semestre de 2008. En primer lugar, se lleva a cabo un rastreo bibliográfico y una revisión histórica, tanto del cine, como de la literatura colombiana con el fin de identificar obras relevantes y definir el corpus de obras literarias y cinematográficas a analizar que cumplan con los criterios estipulados para la selección del corpus. Algunos de los parámetros que guiaron esta selección inicial fueron los siguientes: obras literarias adaptadas al cine; el género elegido es la novela, y el largometraje de ficción, para el caso del cine; la periodización es importante; el tiempo de la historia narrada debe estar enmarcado en el siglo XX; la obra literaria debe ser de autoría de un escritor con nacionalidad colombiana, aunque la cinta cinematográfica puede ser dirigida por un extranjero; dado que la 
novela precede al filme, se parte de la base de que ésta ya relata la identidad colombiana; y, por último, que relate personajes colombianos.

Luego de tener un corpus de obras (adaptaciones) seleccionadas que cumplieran con los criterios definidos, el paso siguiente es la revisión bibliográfica sobre la crítica que tanto en literatura como en cine existe sobre las novelas y películas del corpus. En principio fueron 16 obras seleccionadas, después del análisis crítico se conservan:

1924 La Vorágine escrita por José Eustasio Rivera y adaptada con el nombre de Abismos de amor en 1945 por Miguel Zacarías.

$1961 \mathrm{El}$ coronel no tiene quien le escriba de Gabriel García Márquez y adaptada por Arturo Ripstein en 1999.

1969 Caín escrita por Eduardo Caballero Calderón y adaptada por Gustavo Nieto Roa en 1984.

1971 Cóndores no entierran todos los días escrita por Gustavo Álvarez Gardeazábal y adaptada por Francisco Norden en 1984.

1973 La mansión de Araucaima escrita por Álvaro Mutis y adaptada por Carlos Mayolo en 1986.

1981 Crónica de una muerte anunciada escrita por Gabriel García Márquez y adaptada por Francesco Rossi y Tonino Guerra en 1987.

1985 El amor en los tiempos del cólera escrita por Gabriel García Márquez y adaptada por Mile Newell en 2007.

1994 La virgen de los sicarios escrita por Fernando Vallejo y adaptada por Barbet Schroeder en el 2000.

1997 Perder es cuestión de método escrita por Santiago Gamboa y adaptada por Sergio Cabrera en 2005.

1999 Rosario Tijeras escrita por Jorge Franco y adaptada por Emilio Maillet en 2005.

2002 Satanás escrita por Mario Mendoza y adaptada por Andy Baiz en 2007.

2002 Paraíso Travel escrita por Jorge Franco y adaptada por Simón Brand en 2008.
Para recopilar la información obtenida en la revisión crítica se elaboró una ficha técnica para la identificación del corpus; en ella se consignaron datos bibliográficos tales como nombre de la historia literaria o cinematográfica, nombre del capítulo, artículo o ensayo, y páginas en el que se encuentra, autor y datos bibliográficos de la publicación consultada (editorial, año, ciudad) y datos descriptivos: obra del corpus y cita, observaciones o comentario crítico. Se consideró un listado de publicaciones, entre manuales, libros de historia, crítica y revistas especializadas, tanto en literatura como en cine que se puede consultar en la bibliografía de este artículo.

\section{VIOLENCIA, UN TEMA RECURRENTE EN LA NARRATIVA COLOMBIANA}

La violencia ha sido un tema omnipresente en la literatura y en el cine nacional. Es un reflejo de la historia del país con una guerra no admitida que tiene más de cincuenta años. Esta temática ha sido la materia prima para muchas novelas y películas colombianas, en las cuales se ha puesto en primer plano o como telón de fondo. Podríamos decir que además de ser un aspecto recurrente es el gran tema de la narrativa nacional.

Las películas del corpus de la investigación incluyen obras literarias y películas que abarcan el espectro de la violencia, sus diversas formas y consecuencias: desde el conflicto de las selvas caucheras de Colombia que trasciende lo local en La vorágine, a la violencia política en Cóndores no entierran todos los días y sus consecuencias como el desplazamiento y la desigualdad de clases en Terremoto -Pisingaña- y Caín, pasando por la violencia guerrillera de los 60 y 70 en La guerra de los tigrillos-Canaguaro -, la del narcotráfico de los años 80 y 90, expresada en la sicaresca de La virgen de los sicarios y Rosario Tijeras, hasta la delincuencia cotidiana de las ciudades en Perder es cuestión de método o la locura y el asesinato en Satanás o La Mansión de Araucaima.

En las obras de Gabriel García Márquez, la violencia es una sensación continua en el ambien- 
te; en El amor en los tiempos del cólera el tema no es protagónico, pero hace parte del contexto, como lo confirma la descripción del viaje en globo de Fermina Daza y Juvenal Urbino:

Volaron sobre el océano de sombras de los plantíos de banano (...). El ingeniero del globo, que iba observando el mundo con un catalejo, dijo: "Parecen muertos". Le pasó el catalejo al doctor Juvenal Urbino, y éste vio las carretas de bueyes entre los sembrados, las guardarrayas de la línea del tren, las acequias heladas, y dondequiera que fijó sus ojos encontró cuerpos humanos esparcidos. Alguien dijo saber que el cólera estaba haciendo estragos en los pueblos de la Ciénaga Grande. El doctor Urbino, mientras hablaba, no dejó de mirar por el catalejo. -Pues debe ser una modalidad muy especial del cólera -dijo-, porque cada muerto tiene su tiro de gracia en la nuca. (125)

Asimismo, en El coronel no tiene quien le escriba, el autor es claro en afirmar que si bien no es una novela de la violencia, sí lo es de las consecuencias en los sobrevivientes. Por último, se muestra otra forma de violencia como la venganza y sus móviles que se encuentran en Crónica de una muerte anunciada, en la historia de la vendetta de los hermanos Vicario ante la deshonra de su hermana.

La crítica encontrada sobre las obras tanto literarias como cinematográficas se divide en calidad y cantidad de estudios, comentarios, reseñas, análisis. Algunas obras del corpus seleccionado sin duda recibieron en el pasado y posiblemente seguirán recibiendo más atención que otras con las cuales comparten un tema en común, una misma realidad, e incluso los mismos escenarios. En general, se trata de novelas que por diversas razones ocupan un lugar importante en las historias y la crítica literaria del país. Es el caso de Crónica de una muerte anunciada de 1981, una de las obras literarias adaptadas al cine sobre la que más se ha escrito, acaso menos por ella misma que por el interés que suscita su creador.

Gabriel García Márquez publica CMA pasados seis años desde su última novela, El otoño del patriarca publicada en 1975, por ello, había gran expectativa sobre su nueva publicación; sin embargo, García Márquez decide tomar otro rumbo con esta narración basada en hechos reales ocurridos muchos años antes en Sucre, un pueblito de la costa caribe. No se sabe exactamente cuándo la empezó a escribir, pero esperó hasta que el último de los implicados muriera para emprender esta tarea. Esta publicación es reseñada en numerosos estudios de literatura, en historias de la literatura, en la crítica, y en fin, en diversas publicaciones literarias del país. Asimismo, se realizan análisis sobre sus personajes, la historia narrada, el tema propuesto, se lanzan hipótesis sobre la culpa o la inocencia de Santiago Nazar en el perjuicio sufrido por Ángela Vicario a los ojos de la sociedad, el pueblo y su familia. De igual manera, se analiza la participación y complicidad del pueblo entero en el asesinato de Nazar, con la intencionalidad que entraña el silencio del pueblo entero.

Fernando Ayala Poveda en su Manual de literatura colombiana de 1984 dedica un apartado completo a Gabriel García Márquez, luego de una breve biografía del novelista, comenta algunas de sus obras más representativas, CMA entre éstas; específicamente se refiere al uso de la ironía de la historia en la que todos los personajes hacen parte de un mismo engranaje; mientras el Manual de literatura colombiana de Procultura, en manos de Martha Canfield, dedica un capítulo completo al Nobel colombiano y a su obra; una de las novelas mencionadas es CMA, reseña las particularidades de su nacimiento, cómo se vio obligado el escritor a esperar debido a una promesa de contar la historia sólo cuando los implicados no se vieran señalados, las particularidades en general de la obra e incluso es denominada una pequeña joya, 156 páginas de absoluta perfección (281). Asimismo, la autora se ocupa de la adaptación cinematográfica, en su opinión, ésta es realizada con un casting de alta taquilla y alta calidad. En otros apartados del Manual de Procultura se menciona la obra como "una novela breve y perfecta en su realización, centrada en la tentación y contemporánea incapacidad de evadir el destino" (288). En textos como Estudios colombiano. Asociaciones de colombianistas 
veinte años. 1983-2003 dedica todo un ensayo de Michael Palencia-Roth a la consideración de CMA como el anti-Edipo de García Márquez y otro más de Rhonda Dahl Buchanan sobre el arte narrativo como exorcismo en CMA.

Lo propio ocurre con El coronel no tiene quien le escriba, escrita en el año 1957 por García Márquez. La crítica evidencia la acogida por parte de lectores y estudiosos. El coronel es una de las obras principales dentro de la Literatura de García Márquez, ya que de acuerdo con Conrado Zuluaga en "La espera del viejo combatiente" publicado en la edición de la novela que hace Norma, "pocas narraciones en el panorama literario colombiano, alcanzan el equilibrio, la seguridad y la perfección de que hace gala la historia del viejo combatiente" $(2008,30)$. Se le valora incluso por su poder argumentativo con el que impulsa estas ideas acertadas en pos de presentar las condiciones por las que Colombia ha crecido a través de los años con un halo de país agresivo y sangriento, dominado por intereses ajenos a los más pobres.

Otras obras que hacen parte de corpus seleccionado como Caín de Eduardo Caballero Calderón no corren con igual suerte, Ayala Poveda, por ejemplo, menciona esta obra junto a otras tres novelas como obras no logradas, "El arte de vivir, Caín, El buen salvaje y La penúltima hora son menos novelas y totalmente artificiosas [...] consideramos que son obras marginales, malogradas casi totalmente" (313). Mientras que el Manual de Procultura la ignora de lleno, no se encuentra ni una sola mención a la obra, lo que es bastante diciente si se tiene en cuenta la importancia del escritor para las letras colombianas; Eduardo Caballero Calderón es mencionado en algunas páginas del Manual, lo menciona Eduardo Pachón Padilla por sus cuentos y lo señala como un autor que se destaca en la novela; asimismo es reseñada Tipacoque de 1941 como una novela señorial de costumbres de las altiplanicies andinas. En otros textos como Literatura Colombiana de José A. Núñez Segura se mencionan los datos bibliográficos, algunos de los ensayos y dos de las novelas escritas por el
Caballero, El arte de vivir sin soñar y Tipacoque, pero no se hace mención alguna de la novela Caín. De manera similar en Evolución de la novela en Colombia de Antonio Curcio Altamar se mencionan las diferentes novelas de Caballero Calderón, pero no hay ninguna mención a Caín.

Un caso similar, aunque más evidente es el que ocurre con la novela El terremoto (1986) de Germán Pinzón. En el Manual de Ayala Poveda no se encuentra ninguna mención ni al autor ni a la obra. Curcio Altamar en Evolución de la novela en Colombia tampoco lo considera entre los autores reseñados y el Manual de Procultura en el capítulo de los Nadaístas se menciona como ganador del premio en el Congreso Nadaísta de 1966, pero no se ofrecen detalles de la obra o su autor.

Otra historia se cuenta de obras como La vorágine de José Eustasio Rivera publicada en 1924, ya que el tiempo no ha hecho más que confirmar la importancia de esta obra, su carácter pionero y su modernidad. Una obra fundamental que instaura la novela de la identidad latinoamericana. Sin duda La vorágine es una de las grandes obras de la literatura colombiana y latinoamericana. Es junto a María (1867) de Jorge Isaacs y Cien años de soledad (1967) de García Márquez, como lo señala la historia y lo confirma Monserrat Ordóñez en el Manual de literatura colombiana, una de las tres obras de la literatura colombiana que han aportado a la literatura latinoamericana $(1988,435)$. Seymon Menton, en La novela colombiana Planetas y satélites, por ejemplo, la ubica al nivel de las grandes obras de la literatura universal y la compara con La Divina comedia de Dante o la Eneida de Virgilio: "El infierno de Rivera se encuentra en las selvas caucheras de Colombia, pero esto no impide que también se identifique con el bosque oscuro del infierno de Dante o con La vorágine negra de la Eneida de Virgilio" (1978, 148). Margarita Palmer señala, por su parte, que esta obra no solo ha recreado los mitos de carácter universal, sino que ante todo ha tomado como elemento central la leyenda de origen americano, el pensamiento mitológico de los indígenas $(2007,141)$. 
Para Fernando Ayala Poveda en el Manual de Literatura publicado en 1984 esta obra instaura la novela de la identidad y además perfecciona y agiganta la identidad latinoamericana. El tema, la violencia, real, social, y de impunidad está presente en toda la historia narrada como lo explica Alfonso Arocha en su artículo en Poligramas (2007, 148). Para Javier Arango Ferrer en Horas de la literatura colombiana, la novela de Rivera no es Colombia sino la definición misma de la violencia (1978, 110).

Otra de las obras adaptadas encontradas es Cóndores no entierran todos los días, una de las pocas adaptaciones que no han decepcionado al público, ni a la crítica, ya que por ambos recibe una crítica positiva. En más de treinta obras consultadas para el análisis, siete la referencian de una manera muy positiva, porque es considerada como una de las mejores novelas sobre el periodo de la Violencia en Colombia. Esta novela causa impacto en la literatura porque aborda desde una perspectiva diferente esta temática, puesto que se muestra desde una postura nueva al héroe y recrea una atmósfera provinciana muy propia del Valle, especialmente de Tuluá. Está reseñada positivamente porque Gustavo Álvarez Gardeazábal recoge todos los elementos que hacen posible el desarrollo íntegro de la ciudad, convirtiéndolo en un lugar mágico, en el cual se evidencian las costumbres y raíces de esta región del país, que generalmente anhela los tiempos pasados, ya que los actuales se consideran peores. Esos anhelos del pasado se convierten por lo general en temores, y eso hace que en esta obra literaria sea evidente el miedo a una realidad que consideran peligrosa e imposible de resolver. En la mayoría de las citas en las cuales está Cóndores referenciada, se encuentra abordado el tema de la mujer y su papel dentro de esta obra, puesto que son ellas las que sobresalen por su papel en la familia y por la capacidad de Álvarez Gardeazábal de unir en una mujer las características de todas y narrar estas posturas desde allí.

Mientras que a El amor en los tiempos del cólera recibe una crítica fuerte, al ser considerada una novela menor rango dentro de la obra del Nobel colombiano, no tiene el nivel de un clásico, como lo señala Mempo Giardinelli en la Revista Lingüística y Literatura: "Me atrevo a decir que esta novela no se recordará dentro 100 ó 200 años". Considera además que el autor llama más la atención sobre su virtuosismo que sobre lo narrado. El tema de la novela es el amor romántico, el amor imposible durante más de 50 años y la vejez. Como lo señala Guardinelli: "La recuperación y la dignificación de la vejez. La idea de la vejez hermosa. García Márquez impone la belleza de los amores otoñales".

Por su parte, Paraíso Travel (2002) de Jorge Franco es definida por José Manuel Camacho como un retrato vivo sobre la transculturización y la identidad colombiana. "El protagonista adquiere en la lejanía conciencia de su identidad. La circunstancia, dice el narrador, era para sentir dolor y rabia con una patria que no ofrece nada que no sea sangre y muertos y un futuro de pobreza" (2007, 104). El tema es la búsqueda del sueño norteamericano como consecuencia de la violencia (inmigrantes colombianos en Nueva York) y sus consecuencias, el desarraigo y la desarticulación de la identidad. La novela enfatiza en la historia de amor; la película, en la emigración.

En el caso de obras como La Mansión de Araucaima escrita en 1973 por Álvaro Mutis llama la atención que sea un relato gótico de tierra caliente como el mismo autor lo ha nombrado, por tratarse de dos palabras que designan algo casi excluyente: gótico y caliente y la sugestión que en el lector puede generar esa combinación. Como obra literaria es analizada tanto por su tema: pasiones que se avivan en un recinto rodeado por la selva, que crea una atmósfera de perfidia y demencia que sostiene la trama narrativa y evidencia el desenlace de la ficción, sus excéntricos personajes procedentes de universos contradictorios y disímiles y por su estructura:

Se trata de una obra abierta, una serie de fragmentos o figuras que el lector habrá de armar a su gusto. Se trata, en definitiva, de una metáfora, 
y una metáfora, lo sabemos bien, es la sustitución, en el interior de un código, de un término por otro, en virtud de una similitud instituida y luego encubierta, como lo anota Umberto Eco, en La estrategia de la ilusión (Cobo Borda, 1997: 286 y 287)

Muchos dicen que no es propiamente una novela, sino unos apuntes que Mutis escribió por un deseo del director español Luis Buñuel de hacer una película gótica, pero fue Carlos Mayolo, un colombiano quien la adaptó. Resulta interesante el trabajo de Mutis para la crítica en general, ya que aborda temas esenciales como la lucidez, la incomunicabilidad, la soledad, el erotismo, e incluso la violencia que convierte a la Mansión en un sitio idílico insólito, esplendoroso, "donde se mueve un río subterráneo de pasiones, intrigas, celos y venganzas. Son las pequeñas miserias humanas, llevadas al punto límite, en las que se pierde toda sensibilidad esencial, no de los sentidos sino del espíritu" (Ardila, 1999:28)

Juan Gustavo Cobo borda dice que Mutis realmente ha logrado la desviación americana de violencia y poesía, dentro del código occidental y, por ello, nos encontramos por fin con nosotros mismos, en la universalidad con que Colombia también forma parte del mundo. De alguna manera en la base de los mitos, tabúes y fantasmas sociales se construye identidad cultural.

Ilona llega con la lluvia, del mismo autor, publicada en 1987 hace parte de lo que puede llamarse la trilogía del Gaviero, las otras dos novelas son: La nieve del almirante (1986) y Un bel morir (1989), que después de conocer la totalidad de la obra de Mutis, muchos críticos han desplazado la designación trilogía para otorgarle la de saga, esto se debe a que existe un personaje, que surge de la poesía del escritor, y que se configura como la criatura que más estrechamente se identifica con él y que mejor lo representa, incluso, se dice que es el álter ego de Mutis; se trata de Maqroll el Gaviero, el protagonista de gran parte de la narrativa de Mutis. En general, los temas de Mutis, tanto en poesía como en prosa son el deterioro, la desesperanza, el viaje, el exilio y la elusiva búsqueda de una trascendencia, temas que se evidencian en Ilona; Maqroll habla de un cuerpo arrasado por el trópico, pero este personaje no habita en Colombia, se traslada y se convierte en la representación de un ser cosmopolita que siente nostalgia por su pasado glorioso, que le interesan las reflexiones que hace sobre sus propios viajes, donde su mérito es hallado en el recorrido sin considerar los resultados de los mismos.

Una novela que aparece poco representada en la crítica literaria es Perder es cuestión de método, de Santiago Gamboa, publicada en el 1997 cuyo mayor aporte a la literatura colombiana es cultivar el género de la novela negra. De acuerdo con Oscar Montoya "constituye una exploración en el género de la novela negra [...] La presencia del elemento sentimental, dramático y la constitución psicológica del personaje son los rasgos diferenciadores" $(2005,89)$. Asimismo, se observa la relación que Gamboa intenta establecer con elementos de la cultura popular "las referencias literarias, televisivas, cinematográficas revelan el afán del autor por hacer de la cultura popular y masiva un referente válido en la construcción de obras literarias" (90).

Con respecto a Satanás (2002) de Mario Mendoza, no se encontró registro en los manuales de literatura e historia y crítica literaria, debido a que la novela fue publicada en 2002, y los libros, consultados en años anteriores a éste. Sin embargo, en revistas literarias se encuentra que esta novela ha sido mencionada y ha tenido un protagonismo en la literatura colombiana por haber recibido el Premio Biblioteca Breve de Novela en el año 2002; pese a esto los críticos dicen que no es suficiente para decir que es una buena obra. "La única razón para elaborar esta nota sobre Satanás es el hecho increíble de que le haya sido otorgado el premio Biblioteca Breve, y por un jurado en el que no faltan nombres de calidad reconocida" (Bada Hansen, 2003:110). La crítica apunta que fue un error que esta novela hubiera ganado el premio antes mencionado; se dice que es una ridiculez la manera en que Mendoza trata de explicar las situaciones relatadas, además de la clara 
intención de querer contar la historia a partir de la consigna cinematográfica iLuz, cámara, acción!, "por si acaso la lee un alevín de Quentin Tarantino decidido a hacer una Pulp Fiction ambientada en Bogotá, para que quede claro que aquí se van a lavar los trapos sucios del Mal" (2003:110 a 112).

La novela como producto literario es fuertemente criticada, sin embargo, muchos rescatan el poder o trascendencia que puede tener la historia, ya que aunque aborda un tema tan universal como la maldad que nace desde el interior de cada ser, pero que desemboca en una cruda manifestación de violencia contra el otro, lo plasma en personajes realistas y cotidianos de la capital colombiana que evidencian la absurda diferencia de clases sociales de nuestro país y el desviado funcionamiento de establecimientos políticos colombianos. Pese a los comentarios negativos que suscita esta novela, hay quienes resaltan elementos que de alguna manera pueden llegar a tener peso dentro de la literatura colombiana actual, apuntan que es un libro pequeño y legible que le aporta a la creación del cuerpo de la literatura colombiana.

Otra de las obras abordadas es La virgen de los sicarios escrita (1994) por Fernando Vallejo; en ella se evidencia una realidad cercana, urbana, que se desarrolla en la ciudad de Medellín. Es una obra marcada por la violencia del sicariato. La crítica refleja una obra llena de sangre, dolor y lágrimas, marcada por la violencia que vivió Medellín en la época de los 80, con un lenguaje imponente y grotesco y "tono irreverente Vallejo evoca a Miguel de Cervantes, Jorge Luis Borges, Honorato de Balzac, Tirso de Molina, Antonio Machado, Gunter Grass, para validar sus afirmaciones sarcásticas, cínicas o desacralizadoras" (Jaramillo, María Mercedes, 2000, Vol. II, 17). Así se va construyendo esta obra literaria, entre la desazón de la muerte y lo afanoso del devenir entre la vida de los sicarios. De acuerdo con Juan Fernando Taborda "La ilusión de oralidad en que se basa la estructura narrativa tiene una función esencial, es el recurso apropiado para dar cuenta desde la novela de una realidad que excede todos los límites de la ficción. Le permite mantener al narrador un contacto directo con la vida de la ciudad, expresar con inmediatez su desespero, sus sentimientos encontrados. Le posibilita así mismo utilizar, sin caer en un falso artificio, el lenguaje callejero" (1998, 54). Como realidad, el permanecer con el sicariato exige conocer las necesidades del hoy como lo hace Vallejo, y describir las heridas más profundas que existen en la sociedad colombiana, condicionada a una vida con miedo, hambre, angustia y necesidad, donde el asesinato se convierte en una opción laboral.

\section{LA CRÍTICA CINEMATOGRÁFICA}

La película de Miguel Zacarías (1949), La vorágine, abismos de amor, adaptación de La vorágine es realizada en 1949, tiene en su reparto a la actriz colombiana Beatriz Segura Peñuela conocida artísticamente como Alicia Caro y quien fue una de las primeras actrices colombianas que triunfó en el exterior. Las escasas reseñas y críticas encontradas sobre esta película son dispares, pero la consideran digna de verse y un esfuerzo válido en todo caso. Una de estas críticas a cargo de García Márquez reconoce que pese a su prevención se llevó una sorpresa. Ve defectos en esta adaptación, pero la considera digna y apreciable: "La fuerza de Rivera, la brutalidad del ambiente en que se movieron sus personajes, las violentas pasiones que los empujaron hasta el satánico corazón de la selva, han sido llevados fielmente a la pantalla, quizá con una maestría poco común en la mercancía cinematográfica de México" (Saucedo, 2003:126)

Cóndores no entierran todos los días adaptada por Francisco Norden en 1984, al igual que la novela, esta película fue recibida muy positivamente por la crítica, puesto que la narrativa que utiliza es catalogada como base para una construcción eficiente de temas políticos y sociales, en donde se da cuenta de un universo regional, que reúne todas las características y costumbres de la misma, es decir, es un cine que se devuelve a mirarse en la gente y sus realidades circundantes. Fue una cinta reconocida nacional e internacionalmente gracias a su buena realización; es considerada por 
la crítica como una película respetable, interesante e importante y eso se ve reflejado en la acogida que tuvo en el público, ya que este acudió a los teatros a ver un cine nacional diferente. Es relevante no sólo por su contenido sino también por el cuidado que pone, según la crítica, en todos los pequeños detalles que hacen de las locaciones utilizadas, espacios creíbles, naturales y sobre todo reveladores de una tradición especial, aunque no se puede dejar de lado que el cuidado que se tuvo para la escogencia de los protagonistas y de la mayoría de los personajes secundarios fue en últimas lo que le dio el valor agregado a la historia, ya que sin é, la película no habría tenido la misma fuerza dramática.

Del filme Caín de 1984, de Gustavo Nieto Roa, sólo se encuentran referencias en dos textos de cine; de acuerdo con García Saucedo se rescata que a pesar de la controversia que causó el filme entre la crítica, es el filme colombiano con mayor audiencia, es decir, que caló profundamente entre el público nacional $(2003,49)$. Además, obtuvo premios como el Salón de la Fama en Nueva York y una Catalina de Oro en Colombia, y los premios Antena de la APE y de Colcultura. No obstante, este comentario parece olvidado por la crítica de cine en el país, tal vez por la crítica desfavorable o nula hacia la obra literaria.

En el caso de Pisingaña de Leopoldo Pinzón de 1986 como adaptación de la novela El terremoto de Germán Pinzón, el panorama es similar al anterior; es una obra poco reseñada cuyo mayor logro es el ser ganadora del primer premio en el Concurso Nadaísta de Novela en 1966. La cinta es reseñada por García Saucedo, sin comentarios críticos; afirma que es "una película que intenta denunciar la represión, la enajenación, la violencia activa y pasiva que la sociedad ejerce sobre los miembros de la clase media y sobre sectores de la población campesina" $(2003,158)$. Al igual que la obra literaria su estudio y referencias son casi nulos dentro de la crítica cinematográfica.

La crítica cinematográfica de La Mansión de Araucaima, en adaptación de Carlos Mayolo, la califica de literal y torpe. RH Moreno-Durán en la revista Cinemateca planteó que cuando se ve la película, no se está frente a un texto evidentemente autónomo sino a una obra que nos está contando su relación con la novela. En definitiva cualquier tipo de violencia se gesta en el interior del individuo y es la idea que Mutis quiso expresar para que Buñuel la plasmara en una película. Para muchos, lamentablemente Mayolo no captó la esencia del relato y se limitó a calcar superficialmente el escrito de Mutis. "Si el realizador hubiera sido auténticamente fiel o ingeniosamente independiente la película habría salido mejor, sobre todo, si consideramos que la novela ofrece una serie de pautas que permiten rezarla "cinematográficamente" (1987:16).

Otro de los grandes críticos de la película de Mayolo es Víctor Gaviria, quien en "La adaptación de la literatura al cine". En: Literatura y cine, una tradición de pasiones encontradas hace un comentario pertinente sobre la literalidad y excesiva fidelidad de la película con el texto: "Sacamos la conclusión, entonces, que cuando se respeta demasiado la literalidad del texto original no se produce el efecto buscado que es el que el espíritu de la novela despierte y se encarne en el cine" (Gaviria, 2003:129).

Gaviria concluye entonces que el primer error de la adaptación es tratar de copiar, de imitar, de reproducir los elementos del texto original, tal como lo hace La mansión de Araucaima; lo que tiene que hacer el adaptador es crear un segundo texto basado en asociaciones; el cineasta debe devolverse e indagar por el origen de los personajes, de los lugares, de la historia en general. En medio de estas críticas, se hallan también algunos comentarios positivos frente a la película y el trabajo de Mayolo, por ejemplo Luis Alberto Álvarez en Páginas de cine apunta que en Cali, Carlos Mayolo fue quien más logró aproximarse a plasmar con fuerza y convicción la idiosincrasia vallecaucana, y agrega que el talento del caleño no ha cuajado todavía en un largometraje satisfactorio, pero continúa estando latente (1998: 66). 
La crítica cinematográfica de El Coronel no tiene quien le escriba plantea que se trata de una clara construcción visual y cinematográfica, lo que favoreció quizá que pudiera ser puesta en cartelera alrededor del año 1999, en México, con el guión de Paz Alicia Garciadiego y la dirección de Arturo Ripstein. De acuerdo con César Alzate "Basada en la novela de Gabriel García Márquez, dice un crédito. Y dice otro, escrita por Paz Alicia Garciadiego... aquí no estamos ante la adaptación párrafo a párrafo de una novela -casualmente escrita cámara en mano-, sino ante la re-creación de una historia. Sin limitaciones... la libertad del novelista es grande; la del guionista, casi nula." $(1999,65)$

Esta obra basada en El Coronel refleja la mirada y acogida de su director Ripstein donde se atienden tres miradas desarrolladas paralelamente en su film, tres acontecimientos que denotaran la vida del coronel, la relación con su esposa y la esperanza en su gallo, único recuerdo de su hijo muerto.

La primera: un hombre agobiado por el hambre y la burocracia. Un hombre tenaz que espera y desespera en el muelle aguardando el barco que le debe traer la pensión prometida. Es la historia que de manera más evidente nos viene a los lectores a la cabeza, cuando recordamos al Coronel... la segunda es la historia de amor entre el Coronel y su esposa, como dos enamorados que aún y con la miseria se aceptan, se aman, se cuidan; y la tercera, es la utopía, el "quijotismo" del Coronel al poner su esperanza en un gallo que podría reivindicar el maltrato de la burocracia, de aquellos a los que sirvió y no lo han recompensado (Cervantes, Cristina, 2005).

Sin embargo, la recreación cinematográfica no fue bien recibida en Colombia por el cambio entre personajes y acontecimientos no especificados en la obra literaria, incluso por su contextualización y ambiente que evidentemente hacen falta en la versión de los cineastas; en opinión de Víctor Gaviria haciendo referencia a El coronel de Ripstein y Garciadiego, los colombianos tienen una información adicional sobre la obra, ya hay unos referentes establecidos, que se quieren ver reflejados en la película, pero el director mexicano las modificó sin lograr los objetivos esperado.

Ilona llega con la lluvia, llevada al cine por Sergio Cabrera en 1996, no tiene buena crítica cinematográfica, ya que esta película no es muy reseñada ni es considerada una adaptación representativa en el cine colombiano. De hecho son mencionadas otras películas de Sergio Cabrera como La estrategia del caracol y no esta obra. No obstante, Pedro Adrián Zuluaga en la revista de cine Kinetoscopio, referencia esta película como "la consolidación del star system criollo en el enclenque sistema de producción de nuestro cine nacional. Paradójicamente, de este prometedor caldo de cultivo no cabría esperar más que un amasijo informe, carente de identidad" (Zuluaga, 1996: 91). Esta película no fue bien recibida por los críticos; hablan de Cabrera como un maquillador de la decadencia, gran tema de Mutis, con una extrema estilización, una búsqueda de sofisticación que llevó a la cinta a tener un heterogéneo recibo entre los públicos, ya que según lo hallado lo que no se le perdona a Cabrera fue haber dejado de lado el cine antropológico o el folclorismo: "No hay en cuanto a situaciones, reflexiones, escenarios e intenciones nada particularmente nuevo" (93).

Se dice, además, que la película tiene verdaderos logros técnicos, buen manejo del lenguaje cinematográfico y profesionalismo en el oficio. Aunque esta obra no tenga como objeto central la representación del ser colombiano, García Saucedo, en su Diccionario de literatura colombiana en el cine, apunta que es una metáfora del aventurismo a la colombiana; pero los críticos italianos la catalogaron, cuando se presentó en la "Mostra" de cine en Venecia, como pintoresquismo pasado de moda y como exotismo artificial e inerte, y hablan de ella como un melodrama. La mayoría coincide en que ni la novela ni la película hablan de la identidad colombiana: "la novela de Álvaro Mutis posee un origen europeo que emana de la condición de sus personajes. Al elegir esta obra, 
Cabrera se vio enfrentado con un tejido complejo de articulaciones que enlazan tres historias involucradas al sueño más que a la realidad" (García, 2003: 104 y 105).

En cuanto a la crítica cinematográfica que recibe Satanás llevada al cine por Andy Baiz en 2007, las opiniones son divididas; por un lado, se dice que es una de los mejores logros cinematográficos en Colombia, hablando en términos de producción: factura impecable y excelente manejo del lenguaje cinematográfico, tal como lo afirma el crítico Oswaldo Osorio en Con el diablo adentro publicado en http://cinefagos.net/): "su precisión narrativa, el buen pulso para transmitir sentimientos y emociones con las actuaciones y las situaciones propuestas, así como una concepción visual esmerada en crear imágenes, no sólo con un valor técnico y estético, sino que nos transportan a los espacios y crean atmósferas certeras". Aunque es imposible comparar con expresiones de mejor o peor el libro que la película y viceversa, muchos se atreven a decir que la propuesta cinematográfica supera la literaria, tanto en forma como en contenido. El mismo Osorio menciona más adelante en su artículo que pese a que en Satanás todos los elementos parecen muy bien ubicados-utilizados, hay un vacío, ya que el relato se torna frío, distante y puede llegar a emocionar muy poco. Vale la pena mencionar que según Adriana Mora, en Satanás se siente un esfuerzo voluntario que supera su origen literario, lo que puede entenderse como la clara intención del director por hacer un trabajo esencialmente cinematográfico, que con el poder de sus imágenes permitiera al público ver una obra de autor, independientemente del libro (Mora, 2007: 109 a 111) .

En contraposición a lo comentado por Osorio, Santiago Andrés Gómez señala que Satanás es una película que produce gran estupor, que es agobiante y surte fuertes efectos en el espectador: "El desarrollo de la película es como dicen las palabras que subraya Eliseo en el libro que lee: avanza inexorablemente en una sola línea, y la condolencia que hay en él es de un mutismo infranqueable" (Gómez, 2007:107 a 109).
Resulta valioso mencionar que Satanás es el primer largometraje que Andy Baiz dirige, y según la crítica, es sorprendente y meritorio para el cine colombiano ya que se trata de una de las mejores películas de los últimos años, con una insondable reflexión sobre temas tan universales como los atroces límites entre el bien y el mal, con una narración coherente, homogénea, y fácilmente legible, esto último en palabras de Santiago Andrés Gómez.

La cinta El amor en los tiempos del cólera de Mike Newell (2007), por su parte, reitera que García Márquez es intraducible al cine, pues ninguna de sus obras ha tenido un resultado satisfactorio al ser adaptada, y ésta no es la excepción ya que se le considera una visión parasitaria del libro. La crítica ha sido unánime en afirmar que se trata un nuevo intento fallido por adaptar al Nobel.

Los personajes con quienes es difícil lograr alguna identificación carecen de fuerza, de credibilidad, de calidez, no están trabajados en profundidad. Se les considera distantes. La película se queda en la descripción exterior, sin penetrar en la naturaleza humana como en la novela. De acuerdo con Leandro Márquez: "La cinta convierte en defecto todo lo que en la escritura de García Márquez luce bello y encantador. Así sucede con el personaje central, con el tono general en que se desarrolla la narración, como con el exacerbado romanticismo que en la cinta se vuelve lineal, carente de humor y agotador" (La Butaca).

La película de Simón Brand (2007) adaptación de la novela Paraíso Travel pese a ser una de las películas más taquilleras del cine colombiano, es considerada por la crítica colombiana e internacional como una obra desigual en el aspecto narrativo, en el ritmo y en la credibilidad de sus personajes y cuya fuerza no va más allá de sus imágenes pulidas de estética de videoclip. Como lo señala el crítico español Jordi Revert: "Su interesante jornada hacia el drama del inmigrante y los sueños hechos añicos se ve contrarrestada por contextos escasamente definidos (la urbe no adquiere el protagonismo que debiera)" (La Butaca). 
Para este crítico una de las mayores debilidades de la cinta tiene que ver con el aspecto narrativo: "El montaje abundante en flashbacks no siempre juega a favor de la narrativa de Brand, desde el momento en que intuimos cómo estos se ven mas justificados como válvulas de escape de la trama principal que auténticas reconstrucciones de un pasado o informaciones fundamentales en torno a los protagonistas" (La Butaca)

En La virgen de los sicarios, la crítica cinematográfica realizada por Barbet Schroeder en el 2000, deja un sinsabor no muy lejano a lo ya conocido en lo leído de la novela; se extiende la realidad dominada por la violencia donde pocos son los sobrevivientes en un gran valle de lágrimas. De esta Virgen afirma Víctor Gaviria en La adaptación de la literatura al cine" en el libro Literatura y Cine, una tradición de pasiones encontradas que "se observa detenidamente que muchas de las secuencias de la película son buenas, pero en ella no se expresa un sentido poético. Es extraño, es como una ilustración, plana, secuencia a secuencia. Es demasiado fiel a la novela, es una fidelidad que mata el espíritu poético de la obra" (2003, 143), sin embargo y pese a su literalidad, su narrativa cinematográfica es apreciada y demarcada por los sin sabores de la realidad que Vallejo desde el comienzo enmarcó en su libro.

Finalmente, la última de las cintas consultada, Perder es cuestión de método dirigida por Sergio Cabrera en 2005 -de la que es escasa la crítica cinematográfica que se encuentra-, plantea coincidencias en cuanto al intento del género negro también en el cine; sin embargo, el crítico Óscar Montoya considera que aunque no pertenece por completo al género negro, sí tiene algunas características que la acercan, entre ellas, la intriga detectivesca, la corrupción, el asesinato, la damisela en peligro con tintes de mujer fatal, los antihéroes, la ciudad y lo oculto, la noche y los escenarios marginales.

\section{CONCLUSIONES}

Después de la consulta realizada en las publicaciones seleccionadas durante la investigación se encuentran resultados concluyentes sobre el corpus seleccionado para el proyecto. Estos se dividen en dos categorías: las obras que inicialmente estaban en la selección y luego de la consulta se descubre que no cumplen los criterios básicos expuestos en este artículo; por otro lado, las obras que debido a la crítica analizada dejan de estar en el corpus dado que no cumplen con los criterios de representatividad en la literatura y la cinematografía colombiana, requisito básico al tratarse de una investigación sobre la construcción de la identidad cultural del país.

Entre los resultados de la primera categoría se encuentra la obra Sendero de luz, que había entrado inicialmente en el corpus, pero en la revisión crítica se descubre que se trata de un cuento del escritor Jaime Ibáñez Castro, por ello, no cumple con los criterios iniciales para estar dentro del corpus: novelas llevadas al cine. Un caso similar se presentó con la película Alma provinciana (1925), pues se encontró que la fuente literaria de esta película no era una novela sino una obra teatral -Con el nombre de Isabel en los labios-. Asimismo, se encontró que El drama del quince de octubre (1915) fue el primer largometraje documental del cine colombiano, razón por la cual no cumplía con uno de los requisitos del corpus: ser largometraje de ficción. La obra Ilona llega con la lluvia sufre la misma suerte, al analizar su contenido y su crítica por ser una obra que no representa personajes colombianos, ni se desarrolla en escenarios del país. Ni la historia ni los personajes ni los lugares, incluso, ni los conflictos, nos aproximan a la identidad cultural colombiana. Así pues, estas cuatro obras fueron retiradas del corpus inicial de la investigación.

Otras obras como La vorágine, de gran importancia para la literatura colombiana, presentan dificultades como la poca información de la pelí cula; de La vorágine, abismo de amor, por ser rodada en escenarios fuera del país, Patrimonio Fílmico no conserva ninguna copia, pues no sería una cinta colombiana. Casos como El coronel no tiene quien le escriba, con una adaptación realizada y producida en México, es una de las obras que quedan en 
la investigación por su carácter literario, por lo importante que es el aporte de García Márquez dentro de la literatura colombiana, y por el acompañamiento constante que Ripstein le permitió en su película.

Canaguaro fue otra de las obras que entró en un principio a hacer parte del corpus. Esta obra cinematográfica, hecha en 1981 y dirigida por Dunav Kuzmanich, ha sobresalido en el cine colombiano, puesto que es de la pocas películas que si bien nos narran un tema recurrente como lo es la Violencia, nos la muestra desde el punto de vista rural, campesino, que evidencia una sensibilidad a los problemas sociales por parte del director que en muy pocas ocasiones se puede observar por la gente del común. De ahí proviene la importancia de la obra, ya que, de acuerdo con la crítica, la cinta trasciende la realidad política nacional. Este filme tiene como uno de sus referentes la obra literaria escrita por Eduardo Franco Isaza, bajo el nombre: Las guerrillas del llano, pero infortunadamente para el escritor la novela no tuvo tanta acogida como la tuvo su versión cinematográfica. De hecho, en las obras consultadas no se reseña y en palabras de Isabel Sánchez en Cine de la Violencia, no es una adaptación, sino un guión original.

Entre las obras que no son representativas a la luz de la crítica se encuentra El terremoto que no ha sido referenciada en ninguno de las historias literarias ni en los textos sobre crítica consultada; de igual manera su adaptación al cine, Pisingaña obra de Germán Pinzón de la que únicamente se encuentran dos reseñas que no dan cuenta de su calidad estética. Un caso similar lo constituye Caín de Eduardo Caballero Calderón, un autor reconocido y representativo de la literatura colombiana, pero que en esta obra en particular no se tiene en cuenta; es ignorada por la crítica en el mejor de los casos o señalada como una obra menor que no llega a ser novela, según el crítico Fernando Ayala Poveda.

Es claro que la falta de historias literarias después del año 2000 dificulta la ubicación de obras literarias recientes como Rosario Tijeras -que sólo aparece referenciada en textos críticos o revistas, entre ellos, los colombianistas en su texto de memorias del Congreso desarrollado en Bogotá en el año 2007: Colombia: tiempos de imaginación y desafío- o La Virgen de los sicarios, abordada sólo por Seymor Menton en La novela colombiana, publicada en el año 2007 y en Literatura y Cultura (2000). Y mucho más difícil aún es el caso de Perder es cuestión de método, que sólo es referenciada rápidamente por Luz Mary Giraldo en un artículo sobre los últimos 30 años de narrativa en Colombia, aparecido en la revista HojasUuniversitarias, en el año 2002.

\section{REFERENCIAS BIBLIOGRÁFICAS}

Alsina, Miguel Rodrigo. 1996. "Minorías étnicas, identidades y medios de comunicación". Signo y Pensamiento. Santa Fe de Bogotá. Vol. 15, No. 29, Jul.-Dic. pp. 39-48.

Arango Ferrer, Javier. 1993. Horas de literatura colombiana. Medellín. Ediciones Autores Antioqueños. Secretaría de Educación y cultura. Editorial Ealón.

Ardila Clemencia, Arana Chamer. 1999. "La mansión de Araucaima. Laberinto siniestro". En: Con-Textos. Revista Semiótica Literaria. Vol. 2. No. 13. Mayo. Universidad de Medellín. pp. 15-28.

Arocha, Alfonso. 2007. "Retórica testimonial entre verosimilitud y ficción en La vorágine". En: Poligramas. No. 28, Universidad del Valle. Escuela de estudios literarios. pp. 131-153.

Ayala Poveda, Fernando. 1984. Manual de literatura colombiana. Bogotá. Educar Editores. 
Bada Hansen, Ricardo. 2003. "Amok se escribe sin hache: Satanás de Mario Mendoza". En: Cuadernos de Literatura colombiana. Maestría en literatura colombiana. Universidad de Antioquia No. 12, enero- junio. pp. 110-112.

Cadavid Marulanda, Álvaro. 2006. La memoria visual de la narrativa colombiana en el cine. Medellín. Universidad de Antioquia.

Camacho Delgado, José Manuel. 2007. "Fronteras con espinas: el sueño neoyorkino en Paraíso Travel". En: Revista Con-Textos. Vol. 19, No. 39. pp. 99-11.

Canfield, Martha. 1988. "Gabriel García Márquez: El amor en los tiempos del cólera". En Manual de Literatura Colombiana. Tomo II. Procultura. Planeta. Bogotá. pp. 335-349.

Cervantes, Cristina. 2005. "El Coronel sí tiene quien le escriba. La adaptación / traducción: genotextos / endotextos". En Razón y palabra. No. 46. Tecnológico de Monterrey, Campus Monterrey, México.

Cobo Borda, Juan Gustavo. 1989. Clásicos colombianos Procultura. Álvaro Mutis. Bogotá. Procultura.

Collazos, Oscar. 2008. "García Márquez: la soledad y la gloria". En El coronel no tiene quien le escriba. Bogotá: Ed. Norma Cara y Cruz.

Curcio Altamar, Antonio.1975. Evolución de la novela colombiana. Bogotá. Instituto colombiano de cultura.

García Canclini, Néstor. 1990 Culturas híbridas. Estrategias para entrar y salir de la modernidad. México: Grijalbo.

García Canclini, Néstor. 1995. Consumidores y ciudadanos. México: Grijalbo.

García Canclini, Néstor. 1999. Silva, Arciniegas, Mutis y García Márquez. Bogotá. Imprenta Nacional de Colombia.

García Canclini, Néstor. 2006. La cámara y la tinta, Estudios sobre el séptimo arte. Bogotá. Universidad Externado de Colombia. Departamento de Publicaciones.

García Canclini, Néstor. 2002. "La cultura visual en la época del posracionalismo. ¿Quién nos va a contar la identidad?". Nueva Sociedad. Caracas. No. 180-181, Jul.-Oct. pp. 250-262.

García Dussán, Pablo. 2006, 2007. Literatura Thanática: Búsqueda de una memoria común. Bogotá. Premio Nacional de ensayo literario Hernando Téllez.

García Saucedo, Jaime. 2003. Diccionario de literatura colombiana en el cine. Bogotá. Panamericana Editorial Ltda. p. 105.

Gaviria, Víctor. 2003. "La adaptación de la literatura al cine". En Augusto Escobar Mesa. Literatura y cine, una tradición de pasiones encontradas. Medellín: Comfama. pp. 127-145.

Giardinelli, Mempo. 1986. "El amor (y la falsedad) en los tiempos del cólera". En Revista Lingúistica y literatura. Departamento de Lingüística y Literatura. U de A. Editorial U. de A. pp. 23-29.

González, Catalina. 1997. "Identidad, alteridad y comunicación: Definiciones y relaciones". Signo y Pensamiento. Santafé de Bogotá. Vol. 16, No. 30, pp. 77-84, Ene.-Jun.,

González Luna, Javier. 1995. "Álvaro Mutis: El retorno". En: Cuadernos de literatura. Bogotá. Vol. 1 No. 1. Enerojunio. pp. 47-65.

Gómez, Fabio. 2008. "Emergencia del mito americano en La vorágine". En Revista Poligramas, No. 30. Escuela de Estudios literarios, 2008. Universidad del Valle. pp. 239-266. 
Gómez Restrepo, Antonio. 1946. Historia de la literatura colombiana. Bogotá: Imprenta Nacional.

Jaramillo, José Eduardo (selección y prólogo). 2005. Estudios colombianos. Asociación de colombianistas veinte años 1983-2003. Denison University.

Jaramillo, María Mercedes. 2000. "Fernando Vallejo: Desacralización y memoria". En: Ángela Inés Robledo, Betty Osorio, María Mercedes Jaramillo. Literatura y Cultura. Narrativa colombiana del siglo XX.. Vol. II. Bogotá: Ministerio de Cultura.

Martínez Pardo, Hernando. 1978. Historia del cine colombiano. Ed. América Latina, Bogotá.

Menton, Seymour. 1978. La novela colombiana: planetas y satélites. Bogotá. Fondo de Cultura Económica.

Montoya, Óscar. "Perder es cuestión de método de Santiago Gamboa: Los nuevos caminos de la novela negra en Colombia". En: Estudios de literatura Colombiana. No. 16, 2005, pp. 73-90.

Moreno Chuquen, Liz. 2008. "Reseñas. Jaramillo Morales, Alejandra. Nación y melancolía: narrativas de la violencia en Colombia (1995 -2005)". En: Literatura: Teoría, historia, crítica. No. 10, octubre. pp. 406-412.

Núñez Segura, José A. 1959. Literatura colombiana (sinopsis y comentarios de autores representativos). Medellín: Editorial Bedout.

Ordoñez, Montserrat 1988. "La vorágine. La voz rota de Arturo Cova". En Manual de Literatura Colombiana. Tomo I. Procultura. Planeta. pp. 433-518.

Ortega Torres, José Joaquín. 1934. Historia de la literatura colombiana. Bogotá: Escuela Tipográfica Salesiana.

Pineda Botero, Álvaro. 1990. Del mito a la postmodernidad. La novela colombiana de finales del siglo XX. Bogotá. Tercer Mundo Editores.

Pineda Botero, Álvaro. 1999. La fábula y el desastre. Estudios críticos sobre la novela colombiana 1650-1931. Medellín. Colección Antorcha y Daga. Fondo Editorial Universidad Eafit.

Pineda Botero, Álvaro. 2001. Juicios de residencias: La novela colombiana 1934-1985. Medellín. Universidad Eafit.

Pineda Botero, Álvaro. 2006. La esfera inconclusa. Novela colombiana en el ámbito global. Medellín. Editorial Universidad de Antioquia.

Piotrowski, Bogdan. 1988. La realidad nacional colombiana en su narrativa contemporánea. Instituto Caro y Cuervo. Bogotá. p. 157.

Rivera Rojas, Álvaro Luciano. 2000. "Ilusión y verdad en El amor en los tiempos del cólera". En Revista de la Facultad de Ciencias Humanas y sociales. Vol. 5 No. 6. Universidad del Cauca. Impresión Taller editorial Universidad del Cauca, pp. 20-32.

Rivera Rojas, Álvaro Luciano. 2000. "Procesos de destinación en El amor en los tiempos del cólera". En Revista de la Facultad de Ciencias Humanas y sociales. Vol. 4, No. 4, Universidad del Cauca. Popayán. Junio 2000. pp. 41-45.

Sánchez Isabel. (Comp.) 1987. Cine de la Violencia. Bogotá: Universidad Nacional.

Sánchez Noriega, José Luis. 2000. De la literatura al cine. Barcelona: Ediciones Paidos Ibérica, S.A.

Taborda Sánchez, Juan Fernando. "Oralidad y escritura en La virgen de los sicarios". En: Estudios de Literatura Colombiana No. 3. 1998. pp. 50-56. 
Valero, Silvia. Cuadernos de literatura Homenaje a Eligio García Márquez (1947-2001)". Vol. IX. No. 17 enero-junio de 2003. Bogotá: Pontificia Universidad Javeriana. Facultad de Ciencias sociales - Departamento de Literatura.

Vallejo, Olga y otros. 2007. Fuentes para el estudio historiográfico de la literatura colombiana 1867-2007 FEHLC. Medellín: Universidad de Antioquia.

Vargas Cantillo, Germán. 2008. "El coronel no tiene quien le escriba". Ed. Norma Cara y Cruz. Vida y obra. Sección Cruz. La espera del viejo combatiente Bogotá - Colombia.

Williams, Raymond. 1980. Una década de la novela colombiana. La experiencia de los setenta. Bogotá. Plaza E Janes.

Williams, Raymond. Compilador. 1985. Ensayos de Literatura colombiana. I Encuentro de colombianistas norteamericanos. Bogotá. Plaza \& Janés.

Zuluaga, Conrado. 2008. El coronel no tiene quien le escriba. Ed. Norma Cara y Cruz. Vida y obra. Sección Cruz. "La espera del viejo combatiente" Bogotá - Colombia.

Álvarez, Luis Alberto. 1989. "Historia del cine colombiano". En: Nueva historia de Colombia. Bogotá. Vol. VI. Capítulo 9. Planeta.

Álvarez, Luis Alberto. 1998. "Cine colombiano: el estado de las cosas. La perspectiva de la región en el cine colombiano. Reflexiones desordenadas". En: Páginas de cine. Vol. 3 Medellín: Editorial Universidad de Antioquia.

\section{REVISTAS}

Alzate Vargas, César. 1999. "El Nobel no tiene quien lo filme". En: revista Kinetoscopio. Medellín, Colombia. Vol. 10. pp. 64-67.

Carvajal, Edwin Alberto. 2002. Revista de la Facultad de Ciencias Humanas y sociales. "Paraíso Travel o el desencanto del sueño americano". En: Revista U. de A. 269, julio-septiembre. pp. 92-93.

Gómez, Santiago Andrés. 2007. "Satanás, de Andi Baiz Que Dios nos libre". En: Kinetoscopio. Vol 17. No. 79 julio-septiembre. Medellín.

Jones León, Sonia. 2006. "Reescritura del discurso amoroso occidental en El amor en los tiempos del cólera". En Kañina. Revista artes y letras Universidad de Costa Rica. Vol. XXX. Editorial UCR \#2. pp. 43-55.

Losilla, Carlos. 1985. "Gabriel García Márquez. "El amor en los tiempos del cólera". En: Quimera. Barcelona, España. \# 50 Junio. p. 73.

Mayolo, Carlos. 1987. "Carlos Mayolo habla sobre La mansión de Araucaima". Monografía. Revista Cinemateca. Vol. 7 Julio. Editorial Procultura SA. pp. 5-14.

Montoya, Oscar. 2005. "Perder es cuestión de método de Sergio Cabrera:... y contar una historia, también". Revista Kinetoscopio. Medellín. No. 72. pp. 66-67.

Mora, Adriana. 2007. "Andi Baiz, un hombre que ama las imágenes". En revista Kinetoscopio. Vol. 17. No. 79 julio-septiembre. Medellín. Centro Colombo Americano.

Moreno-Durán, RH. 1987. "El falansterio violado En torno a "La mansión de Araucaima". Monografía. En: Revista Cinemateca. Vol. 7 Julio. Procultura S. A. pp. 14-18.

Zuluaga, Pedro Adrián. 1996. "Ilona llega con la lluvia, de Sergio Cabrera. La amistad, entre gotas de lluvia y rayos de sol". En: revista Kinetoscopio. No. 39. Vol. 7, Medellín, Centro Colombo Americano. pp. 92 94. 


\section{CIBERGRAFÍA}

Marques, Leandro. "El amor en los tiempos del cólera". En La Butaca Revista Online http://www.labutaca.net/ films/58/elamorenlostiemposdelcolera.php. Consultado diciembre 2009.

Osorio, Oswaldo. "Con el diablo adentro". En http://cinefagos.net/. Consultado diciembre 2009.

Revert, Jordi. "Paraíso Travel". En La Butaca Revista Online http://www.labutaca.net/films/65/paraiso-travel.php. Consultado diciembre 2009. 